\title{
VOGLIO TEMPO. REFLEJOS EMBLEMÁTICOS EN IL TRIONFO DEL TEMPO E DEL DISINGANNO DE BENEDETTO PAMPHILIJ Y GEORG FRIEDRICH HANDEL
}

\author{
VOGLIO TEMPO. EMBLEMATIC REFLECTIONS IN IL TRIONFO DEL TEMPO \\ E DEL DISINGANNO BY BENEDETTO PAMPHILIJ AND GEORG FRIEDRICH \\ HANDEL
}

Lucía Díaz Marroquín

Universidad Complutense de Madrid

ABSTRACT: Allegorical and emblematic images do not appear exclusively in visual literature: Genres such as the Italian or the Italian-inspired Counter-Reformation oratorios, cantatas and sacred or moral operas often contain images quite similar in form and function to those published in the Seventeenth and early Eighteenth-century European collections of emblems. This article analyses some of these parallelisms in the particular case of Il trionfo del Tempo e del Disinganno (c. 1707), by the librettist and patron of the arts Cardinal Benedetto Pamphilj and the composer Georg Friedrich Handel.

KEYWORDS: Emblem, Opera, Oratorio, Academy, Discourse, Allegory, Rhetoric, Aural, Visual, Pamphilj, Handel, Time, Affects, Passions.

RESUMEN: Las imágenes alegóricas o emblemáticas no resultan exclusivas de la literatura visual: géneros como el oratorio, la cantata y la ópera moral o sacra contrarreformista italiana o de inspiración italiana contienen a menudo imágenes muy similares en su forma y función a las que aparecen publicadas en las colecciones europeas de emblemas en los siglos XVII y XVIII. Este artículo analiza algunos de estos paralelismos en el caso de la obra Il trionfo del Tempo e del Disinganno (c. 1707), compuesta por Georg Friedrich Handel a partir de un libretto del poeta y mecenas Cardenal Benedetto Pamphilj.

PALABRAS CLAVES: Emblema, ópera, oratorio, accademia, discurso, alegoría, retórica, auditivo, visual, Pamphilj, Handel, tiempo, afectos, pasiones. 
La literatura emblemática de los siglos XVII y XVIII suele responder a unos presupuestos formales básicos que consisten en el clásico motto o inscriptio, acompañando a una pictura que ve amplificado su sentido gracias a un epigramma o subscriptio. Teniendo en cuenta el éxito de este modelo en el terreno de la literatura visual, en ocasiones no resulta fácil reparar en la presencia de imágenes o motivos emblemáticos que, esencial o circunstancialmente, puedan no contar con un referente visual. Éste sería el caso, sin embargo, del género y la obra que analiza este artículo: el drama musical en la Roma del cambio del Seicento al Settecento y, de forma particular, el oratorio Il trionfo del Tempo e del Disinganno, estrenado en 1707.

Se trata de una obra excepcionalmente simbólica y muy deudora del ambiente estético y del momento en el que surge, en plena prohibición temporal de los espectáculos operísticos en la Ciudad Santa por decreto papal. Esta prohibición dio lugar a una sustitución de la representación de episodios profanos sobre escenarios operísticos mediante la traducción de elementos dramáticos e imágenes a lo humano por otras a lo divino. La demanda por parte del público del nivel de dinamismo dramático propio de la ópera y el hecho de que tanto los autores de libretti como los compositores musicales participaran indistintamente en uno y otro género dio lugar, de hecho, a que, en ocasiones, esta traducción del género profano operístico a su contrafactum sacro, el oratorio, resultara prácticamente imperceptible.

Il trionfo del Tempo e del Disinganno es fruto de la colaboración entre un autor literario y otro musical que se encuentran entre los más geniales entre los que han ido configurando el discurso artístico europeo en los últimos cinco siglos: el italiano Benedetto Pamphilj y el germano de origen -aunque expatriado de vocación- Georg Friedrich Handel.

Benedetto Pamphilij (Roma 1653-Roma 1730), investido cardenal por el papa Inocencio XI, fue uno de los grandes mecenas de la Roma barroca. Aunque su actividad como coleccionista y promotor de las artes resulta más relevante que ninguna otra de sus facetas, como autor literario compuso varios libretti dramático-musicales que pusieron en música compositores como Alessandro Scarlatti y Georg Friedrich Handel. Fue, además, académico de la prestigiosa Accademia dell'Arcadia, con el nombre arcádico de Fenicio Larisseo (Weller, 1862). Como sistema coetáneo y paralelo al desarrollo de la Universidad italiana, el intrincado sistema de las accademiae que pueblan, primero, la Italia humanista y, enseguida, también la barroca resulta ser una representación muy gráfica del nivel de complejidad que había alcanzado el humanismo en las últimas décadas del Seicento y primeras del Settecento. Frente a la jerarquía característica de la Universidad, las academias presentan la singularidad de constituirse como espacio para la creación artística, así como la de reunir a miembros de ambos sexos. A pesar de que entra dentro de lo convencional el que sus estatutos promuevan la necesidad de dejar a un lado tratamientos y convenciones sociales para centrarse en el estudio o en el disfrute de los textos y de las artes, las listas de sus miembros proporcionan una idea muy clara de hasta qué punto en la mayoría de ellas tenía lugar una celebración del mismo orden social que pretendían despreciar. Sin embargo, es de la soñada subversión estética de las categorías sociales a la que suelen aludir sus estatutos de donde surgen el calor y la creatividad que darán lugar al nacimiento de tantas obras relevantes para la estética y la historia de la identidad artística europea.

A la misma Accademia dell'Arcadia de la que formó parte Benedetto Pamphilij pertenecieron también príncipes políticos y eclesiásticos, autores y diletantes literarios de la categoría de Pietro Metastasio (con el nombre de Artino Corasio) (Weller, 1862), Apostolo Zeno (Emaro Simbolio) (Weller, 1862) o el mismo Alessandro Scarlatti, 
quien también pondría en música otros libretos de Pamphilij (Terpandro Azeriano) (Weller, 1862). Todos ellos, de acuerdo con los principios de la Accademia, se mostraban dispuestos a «romper guerra alle gonfiezze del secolo, e ritornare la poesia italiana per mezzo della pastorale alle pure e belle sue forme», convencidos de la necesidad de desprenderse de todos los aditamentos y de la artificiosidad que habían llegado a caracterizar el discurso literario barroco italiano.

Como patrón de las artes, el cardenal mecenas promovió la construcción de la capilla Doria Pamphilij y la decoración del interior de la galería, para la que configuró, además, una gran colección de pintura flamenca. Su habilidad como coleccionista se extendió a la bibliofilia. Así, en 1704 fue nombrado bibliotecario de la Biblioteca Apostólica Vaticana y archivista del Archivio Segreto Vaticano.

Aparte de poseer la sensibilidad innata de los verdaderos artistas, la faceta de autor de Benedetto Pamphilij se explica mejor teniendo en cuenta la extraordinariamente amplia cantidad de obras artísticas que poseyó o con las que estuvo en contacto. Sus libretos, convertidos en cantatas u oratorios por algunos de los compositores más relevantes de su tiempo, muestran una capacidad de penetración en el, a menudo, confuso territorio de las pasiones humanas que los convierte en un repertorio con personalidad y autonomía propias. Entre estos libretos destacan varios retratos femeninos sobre el tema de la conversión de María Magdalena puestos en música por Alessandro Scarlatti, además de otro, más complejo, para el que Georg Friedrich Handel compondría la partitura de Il trionfo del Tempo e del Disinganno. En los años de la prohibición papal de la ópera, la representación de oratorios y cantatas llegó a sustituir a aquéllas sobre escenarios habilitados en capillas o palacios, proponiendo mitos y protagonistas de origen bíblico o alegórico que servían como contrafacta a lo divino para los per- sonajes operísticos. La protagonista de los libretos de Pamphilij suele ser una mujer, Maddalena, en el caso de las obras de Scarlatti, y el personaje alegórico de la Bellezza, en el libretto puesto en música por Handel, a pesar de que el título moralizante de este último ni siquiera la menciona. Será la trayectoria de esta mujer la que dé lugar a la peripecia dramática en los dos casos, desde el pleno disfrute de su presencia en el mundo, de su juventud y su belleza, hasta el arrepentimiento, su confesión de una supuesta culpa o pecado y el reconocimiento de una "nueva vida" apartada del disfrute de los placeres materiales. El tema no podría encontrarse más cerca de la literatura moralizante de los siglos XVII y XVIII, incluidas las colecciones de emblemas, en las que el tópico del tempus fugit y sus múltiples variantes son algunos de los motivos que más éxito alcanzan [fig. 1].

Si el cardenal Benedetto Pamphilij es el prototipo de hombre que permanece en el centro de su perímetro aristocrático -el

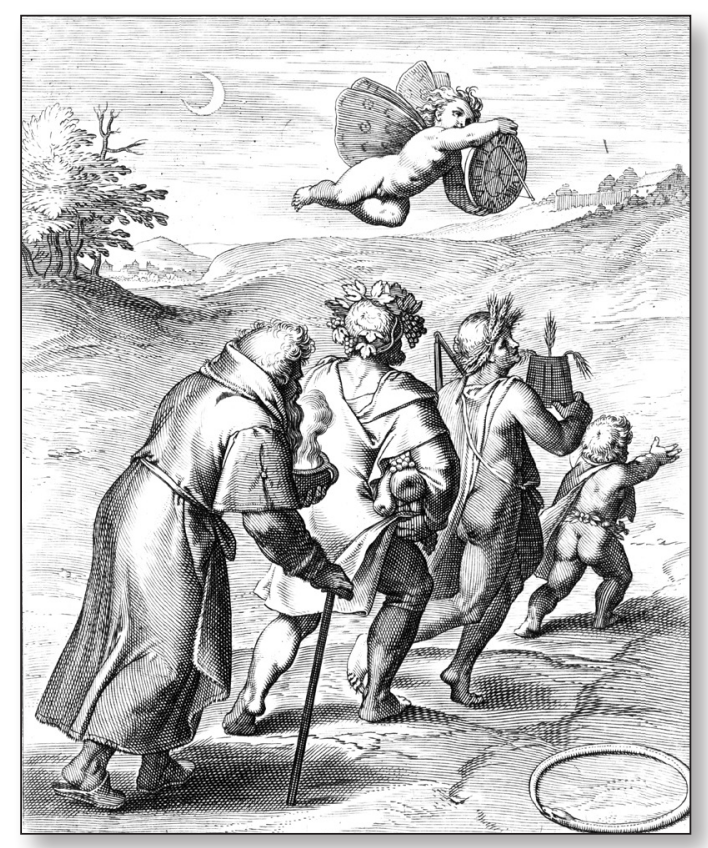

Fig. 1. Otto Vaenius. "Volat irrevocabile tempus». Horatii Flacci emblemata. 1612 
de la Roma barroca y contrarreformista-, con su doble vida académica y eclesiástica pero siempre palaciega, el compositor Georg Friedrich Handel (Halle 1685- Londres, 1759) personifica, en muchos aspectos, el prototipo opuesto. El germano es el expatriado intelectual en permanente viaje creativo hacia el foco cultural-hegemónico de su tiempo: la Roma que sigue irradiando hacia el resto de Europa los logros más acabados en todas las ramas del conocimiento, desde las artes visuales hasta la literatura o la música. El encuentro entre Pamphilij y Handel, a pesar de la diferencia de más de veinte años que los separaba, parece haber sido el de dos espíritus afines, a juzgar por su intercambio intelectual, por la calidad de las obras en las que colaboraron y por el detalle anecdótico de los cumplidos entre lo convencional y lo risueño al talento del joven compositor germano que el cardenal desliza en sus libretos. ${ }^{1}$ Tras iniciar su formación musical en contra de los deseos de su familia en Halle, Handel había entrado en contacto con los Medici italianos, quienes, en 1706, lo invitaron a Florencia. Tras pasar algún tiempo en esta ciudad, decidió dirigirse a Roma, donde entraría en contacto con los que iban a convertirse en sus más sólidos mentores: los cardenales Pietro Ottoboni, académico arcádico bajo el nombre de Crateo Ericinio (Weller, 1862), Carlo Colonna y el mismo Benedetto Pamphilij. De forma particularmente determinante para el desarrollo de su carrera, se encontraría también con el primer príncipe de Cerveteri, Francesco Maria Marescotti Ruspoli, su mecenas más decidido y miembro, igualmente, de la Accademia dell'Arcadia bajo el nombre de Olinto Arsenio (Weller, 1862), a quien dedicaría Il trionfo del Tempo e del Disinganno. La prohibición provisional de los es- pectáculos operísticos en esos años hizo que el compositor tuviera que prescindir de los alicientes de la escena dramático-musical italiana. Sin embargo y como contrapunto, el género del oratorio barroco, alentado por el ambiente contrarreformista y amable de la Congregazzione dell'Oratorio de San Felipe Neri en el que surgieron las primeras obras de este tipo, iba a proporcionarle un campo de experimentación con la interpretación vocal de las pasiones humanas en el que lo acompañaría el cardenal poeta Pamphilij. Es en este ambiente estético en el que desarrolla su juego dramático el cuarteto de personajes que forman las numerosas imágenes emblemáticas que contiene Il trionfo del Tempo.

\section{La Bellezza (Soprano) \\ Il Piacere (Soprano) \\ Il Disinganno (Contralto) \\ Il Tempo (Tenor)}

Como resulta frecuente en obras dramático-musicales proyectadas en función de una ocasión y público determinados pero que, al alcanzar el éxito, vuelven a ser representadas en circunstancias y ante auditorios diferentes, existen varias versiones con diferentes números de catálogo: la obra originalmente representada en 1707 es la catalogada como HWV 46a, y aparece organizada en dos actos, siguiendo así la convención italiana contemporánea para el género del oratorio. En 1737 y ya en Londres, Handel revisó y amplió la obra, dando lugar a una segunda versión, habitualmente conocida como Il trionfo del Tempo e della Verità o HWV 46b. Esta segunda versión en italiano, preparada para ser representada ante el público anglosajón en el teatro del Covent Garden, adoptaba una división en

1. El tono del intercambio se aprecia en la correspondencia que establecen y que comenta H. J. Marx (1983: 107$118)$.

2. Carolyn Gianturco (1994) comenta las implicaciones formales de la división en dos o tres actos para los oratorios compuestos en la Roma de las primeras décadas del siglo XVII. 
tres actos y, por lo tanto, también un aspecto más cercano al de la ópera. ${ }^{2}$ De 1757 data la última de las versiones, que es también el último oratorio en todo el catálogo de G. F. Handel: se trata de una revisión de la música, adaptada a una traducción aproximada del libreto al inglés de Thomas Morell quien, además, escribió el texto para cinco nuevas arias y para once nuevos coros, adecuando así el original italiano al gusto británico. Esta última versión lleva el número de catálogo HWV 71.

El argumento es más alegórico y estático que dinámico. Como tantas veces en el terreno del oratorio, el interés de la peripecia dramática no procede tanto del movimiento y la sucesión de encuentros o efectos escénicos como de la tensión que se establece entre los personajes y que reflejan los números musicales. Tras jurar lealtad al Placer,

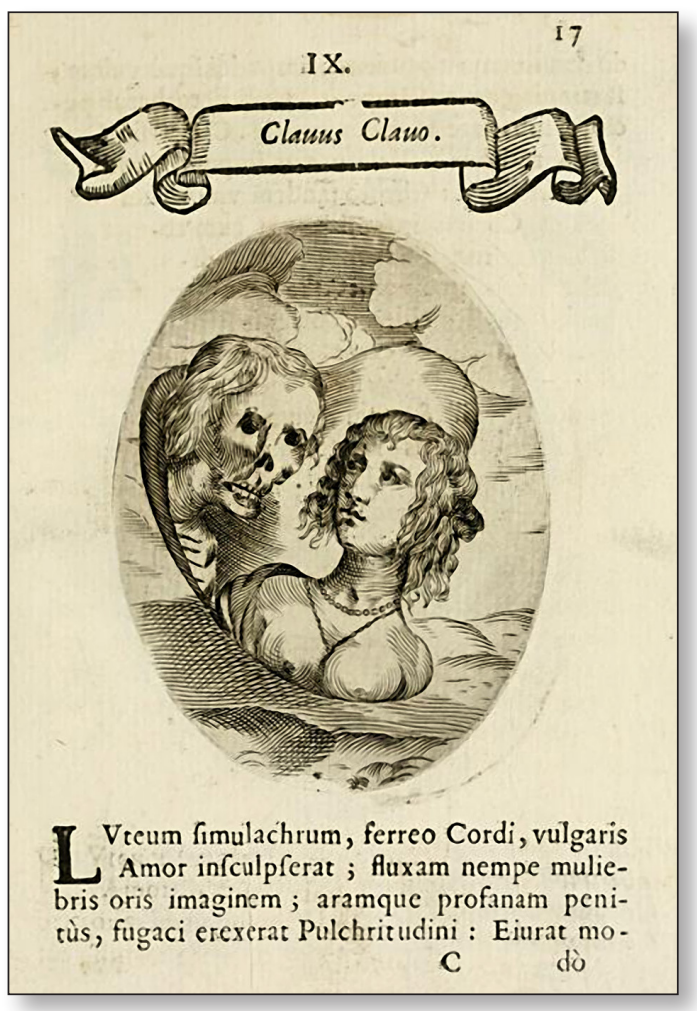

Fig. 2. Francesco Pona, SJ. «Clavus clavo». Cardiomorphoseos, sive ex corde desumpta emblemata sacra. Verona, 1645. tal y como este personaje revela ( Tu giurasti di mai non lasciarmi...»), la Belleza es asediada por el Desengaño y por el Tiempo, quienes le recuerdan la fugacidad de las lealtades terrenales de un modo muy cercano a las imágenes contemporáneas de jóvenes acosadas por figuras alegóricas representando a la muerte y a la decadencia, frecuentes en colecciones de emblemas morales como el Cardiomorphoseos de Francesco Pona [figs. 2 y 3].

El primer acto del oratorio comienza con un aria en la que el personaje de la Bellezza manifiesta ya toda una declaración de intenciones. Es consciente de los efectos que tendrá para ella el paso del tiempo y pretende cambiar de vida antes de que éstos se manifiesten, pero todavía cree disponer de tiempo:

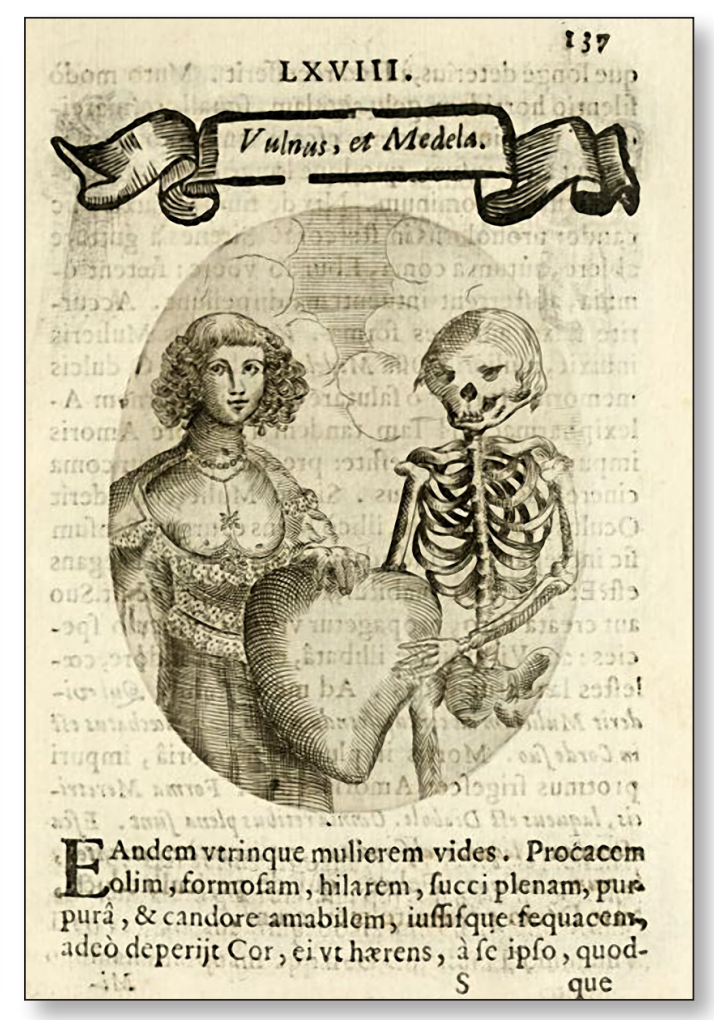

Fig. 3. Francesco Pona, SJ. «Vulnus et Medela». Cardiomorphoseos, sive ex corde desumpta emblemata sacra. Verona, 1645. 
Fido specchio, in te vagheggio

lo splendor degli anni miei

pur, un dì, mi cangerò.

Tu sarai sempre qual sei;

io, qual sono e in te mi veggio,

sempre bella, non sarò.

Los requisitos dramáticos que plantea el aria son mínimos: apenas un accesorio externo, un espejo, tan simbólico del carácter evanescente de los afectos humanos en forma dramático-musical como en forma de pictura emblemática, tal y como propone la tradición simbólica europea desde la Edad Media y tal y como reflejan, ya un siglo antes del estreno del oratorio, colecciones de emblemas como los Amorum emblemata de Otto Vaenius [fig. 4].

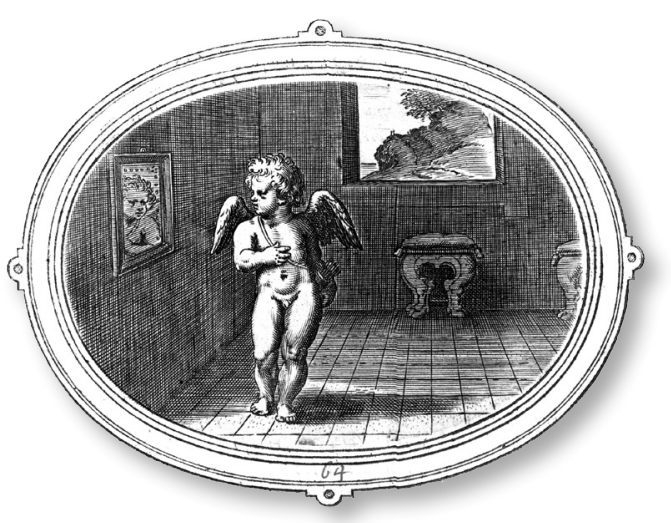

Fig. 4. Otto Vaenius.

"Amans secundus tempus», Amorum emblemata, 1608.

Il trionfo del Tempo e del Disinganno es el primer oratorio en la larga carrera del joven Handel, quien, en el momento del estreno de la obra, contaba sólo con veintitrés años. A pesar de contar con una inspiración melódica prácticamente inagotable, tal y como demostraría en los años siguientes, el compositor de Halle recurrió ocasionalmente, como era habitual en los siglos XVII y XVIII, a la práctica de utilizar una misma melodía o tema para más de una composición, especialmente cuando la primera versión ha- bía obtenido éxito. Éste es el caso del aria «Lascia la spina, cogli la rosa», que aparece por primera vez en esta obra en forma vocal, adaptada a partir de la sarabanda instrumental que el mismo Handel había compuesto en 1704 para su ópera Almira (HWV 1). La misma melodía aparecería de nuevo, sobre el texto "Lascia ch'io pianga mia cruda sorte», en su ópera Rinaldo, compuesta sólo dos años más tarde sobre un libreto basado en la Gerusalemme liberata de Torquato Tasso y que, tras su estreno en el Haymarket Theatre de Londres, pasaría a la historia como la primera ópera en italiano compuesta específicamente para un teatro londinense. Quizá esta segunda versión vocal haya pasado a la historia con más fortuna, pero es la primera, el "Lascia la spina» de Il trionfo del Tempo... la que posee más valor emblemático, reproduciendo otra de las imágenes más características de la literatura moral [figs. 5 y 6], en la que, dependiendo del sentido positivo o negativo que proporcione al emblema el epigramma, se recomienda o se proscribe tomar la rosa evitando el dolor de las espinas:

\section{Lascia la spina \\ cogli la rosa; \\ tu vai cercando \\ il tuo dolor. \\ Canuta brina \\ per mano ascosa, giungerà quando nol crede il cor.}

El motivo del corazón como sinónimo tanto del alma como de la voluntad terrenal es, igualmente, un tema recurrente en la literatura moral y, por extensión, en las compilaciones de emblemas. El aria en que la Bellezza asegura que quisiera contar con dos corazones, uno para seguir el camino virtuoso del arrepentimiento y la penitencia y el otro para entregarlo al placer, es un claro ejemplo de cómo el discurso dramáticomusical contrarreformista logra construir auténticos emblemas sin pictura: 


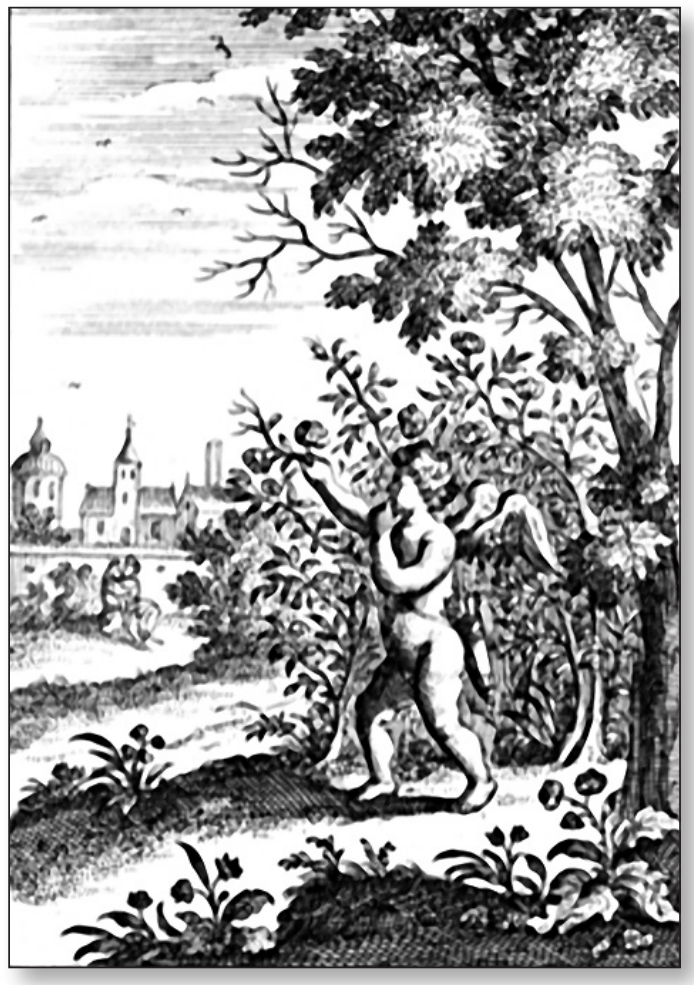

Fig. 5. Anónimo. "Armat spina rosas, mella tegunt apes». Emblemata amatoria, 1690.

\section{Io vorrei due cori in seno \\ Un per darlo al pentimento Al piacer l'altro darei.}

Siguiendo la herencia fisionómica humanista y la tradición médica tanto hipocrática como galénica, el corazón es la imagen anatómica que sirve a los autores del siglo XVII para representar toda clase de desequilibrios relacionados con la fe o con los afectos humanos. No es, sin embargo, la única: familiarizado como estaba con el repertorio simbólico tanto italiano como flamenco, los dos muy abundantes tanto en sus colecciones pictóricas como en sus ricas bibliotecas, Benedetto Pamphilj no podía ignorar el sentido metafórico que poseía la imagen de la nave atrapada en la tempestad. En el caso de los emblemas morales, esta imagen aparece como trasunto del alma perdida y de la falta de fuerzas o de dirección para

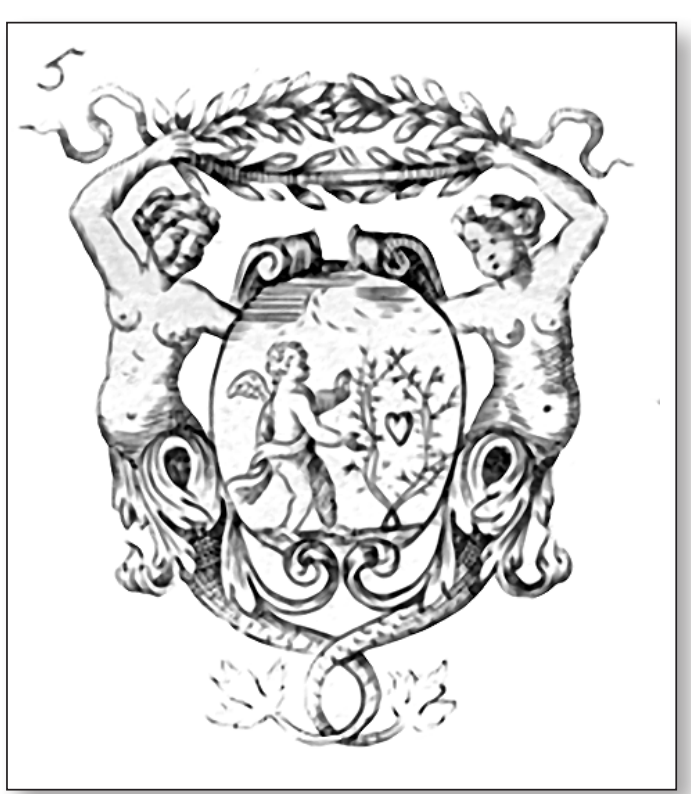

Fig. 6. Daniel de la Feuille. "Un amour prenant un cour au milieu des épines. Gaudium post luctum", Devises et emblemes. Amsterdam, 1691.

luchar contra los ataques de vicios o pecados mientras que, en el de las colecciones a lo humano, figura como símbolo del corazón del amante desorientado. Así lo expresa el personaje del Tempo en el oratorio...

È ben folle quel nocchier

Che non vuol cangiar sentier

E conosce il vento infido.

Navicella, benchè adorna

Torna, torna.

Finchè hai tempo torna al lido.

... y así reproducen la misma imagen los Niederduytsche poemata de Daniel Hensyus [fig. 7].

El recurso de Benedetto Pamphilij a imágenes características de la literatura moral y, en su versión pictórica, de la literatura emblemática contrarreformista resulta constante a lo largo de todo el libreto de este oratorio, tanto en su versión original de 1707 (HWV 46a) como en la ampliada de 1737 (HWV 46b) y en la inglesa de 1757 (HWV 71). Este recurso, que podría pare- 


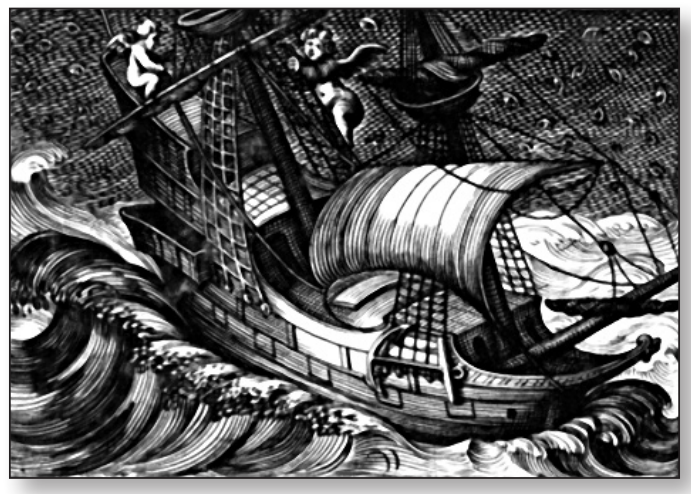

Fig. 7. Daniel Hensyus. "Ambacht van Cupido», Niederduytsche poemata, Amsterdam: Willem Janssen, 1616.

cer explicable en el caso de otros autores de libretti y académicos italianos contemporáneos del cardenal, implica, en el caso de Pamphilij, un nivel suplementario de conocimiento de los temas utilizados por los pintores y grabadores de los Países Bajos, ya que era conocido su gusto por los temas y artistas neerlandeses. Handel, por su parte, tras pasar algunos meses rodeado del lenguaje musical italiano, demuestra haber adquirido ya en el momento de la composición de este oratorio un conocimiento de este género de apenas un siglo de historia que le permite expresarse en él con naturalidad. Y lo hace sobrepasando el nivel del simple uso de las convenciones retóricas características del repertorio dramático-musical italiano para, haciéndolas propias, crear recursos tanto vocales como instrumentales de gran originalidad y capacidad de sugerencia.

Ya la simple asignación de los personajes a determinadas tesituras o tipos vocales resulta significativa, contribuyendo a convertir a éstas en una parte relevante de la pictura emblemática. El hecho de que las dramatis personae sean cuatro y que, de ellas, al menos de acuerdo con la convención italiana contemporánea en términos de género, sólo una, la Bellezza, parezca inequívocamente asimilable a una tessitura vocal femenina $^{3}$ permitiría que el resto de los personajes que componen el cuarteto asumieran una de las otras tres posibilidades entre las cuatro que componen la polifonía desde los tiempos del contrapunto imitativo de tradición franco-flamenca: soprano, alto, tenor y bajo. En lugar de optar por esta distribución convencional, que hubiera traído consigo, además, la posibilidad de distribuir a los personajes en escena (aunque fuera en la escena virtual del oratorio) según la oposición tradicional de las voces agudas masculina y femenina (tenor y soprano) frente a las voces graves (alto y bajo o barítono), Handel opta por una atribución de los papeles poco corriente: a la Bellezza le corresponde una tesitura de soprano, pero su coadyuvante escénico, el Piacere, presenta, por extensión vocal, otra voz de soprano; el Disinganno de la versión de 1707 es una voz de contralto, mientras que el personaje del Tempo está escrito para ser interpretado por un tenor, que es el que aporta homogeneidad sonora al cuarteto mediante su tesitura masculina.

La categoría vocal de tenor, que suelen emplear los compositores cuando pretenden reflejar las mejores cualidades viriles, las que reflejan los más altos logros poéticos y retóricos en el terreno moral, aban-

3. Es conocida la prohibición papal (a menudo infringida) de que fueran mujeres las que interpretaran los personajes femeninos en los Estados Pontificios, lo que no impide ni impidió nunca al público reconocer la condición femenina o masculina de los personajes representados en el drama musical, incluso en los casos en los que tenían lugar cambios de género en escena mediante la introducción del disfraz y del recurso escénico de la anagnórisis. En ocasiones, un mismo personaje podía ser representado por una mujer en una función y por un castrato en la siguiente. No es así el hecho cantar en tesitura de soprano lo que confiere el género femenino a un determinado personaje, sino el conjunto de su caracterización dramática. En el caso de este oratorio, por ejemplo, mientras que la Bellezza presenta un aspecto inequívocamente femenino, el género del Piacere (otra voz de soprano) resulta mucho más ambiguo. 
dona este cometido en el caso particular de este oratorio para suplantar el papel tradicional de la voz masculina más grave, la de bajo, que suele tener la función de evocar el pesimismo, la protección paternal o la melancolía saturnal. Llevando al extremo la asimilación de la ética a la estética en la distribución de las tesituras, puede comprenderse que la voz ejemplar desde el punto de vista de la retórica viril, la del tenor, se asimile en este caso de forma inusual a la estética manierista de lo terrible, de la amenaza de un castigo entendido como necesario para el logro de la perfección moral, que encarnan habitualmente personajes de bajo ya desde el Seneca L'incoronazione di Poppea de Busenello y Monteverdi, aunque sea en contextos operísticos más cercanos a la celebración de lo humano que el oratorio.

La peripecia que narra Il trionfo del Tempo e del Disinganno es definitivamente femenina. El punto de vista que identifica a la mujer hermosa y llena de vida con la pecadora irredenta resulta claramente misógino desde un punto de vista actual, pero cuando lo que se analizan son discursos poéticos surgidos en los años de Pamphilij y Handel, hay que dejarlo provisionalmente a un lado para continuar apreciando ideas o productos artísticos que puedan seguir resultando válidos. En este contexto, los parlamentos de la Bellezza no tendrían sentido si no fueran emitidos por una voz más aguda y más proclive a la fugacidad de las agilidades y coloraturas que las del resto de los personajes que participan en el oratorio. La suya es la ligereza de la juventud y del pecado, opuesta a la gravitas virtuosa que es el ideal del oratorio. Lo agudo de la tesitura y la capacidad para fascinar al auditorio mediante la articulación de affetti retóricos sólo puede resultar, en este mismo contexto ético y poético, un síntoma de enajenación. Si el objetivo de la representación del oratorio consiste en atraer a la Bellezza hasta un punto de reflexión y gravitas que sí resultan características de los dos personajes considerados como moralmente aceptables dentro del reparto -el Disinganno y el Tempocobra todo el sentido que el coadyuvante de la protagonista en su camino a la perdición, el Piacere, posea una voz igualmente aguda $\mathrm{y}$, por lo tanto, enajenada de toda gravitas virtuosa.

Por último, el hecho de que el cuarteto presente un desequilibrio claro en favor de las tessiture y los timbres femeninos llega a convertirse en un elemento más de la pictura moral, ya que el efecto inmediato es que la voz del único personaje de género claramente masculino dentro del oratorio adquiera credibilidad al evocar las imágenes más tenebrosas. En este aspecto y a pesar de la pertenencia del autor del libreto a los círculos renovadores arcádicos, el oratorio no podría resultar más manierista: la insistencia del Tempo a lo largo de todo el primer acto tiene como propósito acelerar la acción dramática y apresurar a la Bellezza para que tome finalmente la decisión de abandonar al Piacere. El aria del Tempo "Urne voi» cuenta así con todos los elementos necesarios para aterrorizar tanto a la joven alegórica como al público asistente, presentando la conmovedora pictura de las urnas abiertas que muestran los despojos del tiempo, carentes ya de toda luz:

\section{Urne voi, che raggiungete tante belle Apritevi, mostratemi \\ se di quelle qualche luce in voi restò. Ma chiudetevi!, Chiudetevi! \\ Sono larve di dolore, sono scheletri di orrore che il mio dente abbandonò.}

En el terreno instrumental, los grupos de semicorcheas al unísono para toda la cuerda enfatizan en forma de ostinato el sentido del texto (Pamphilij y Handel, 1865: 18) [fig. 8]. 


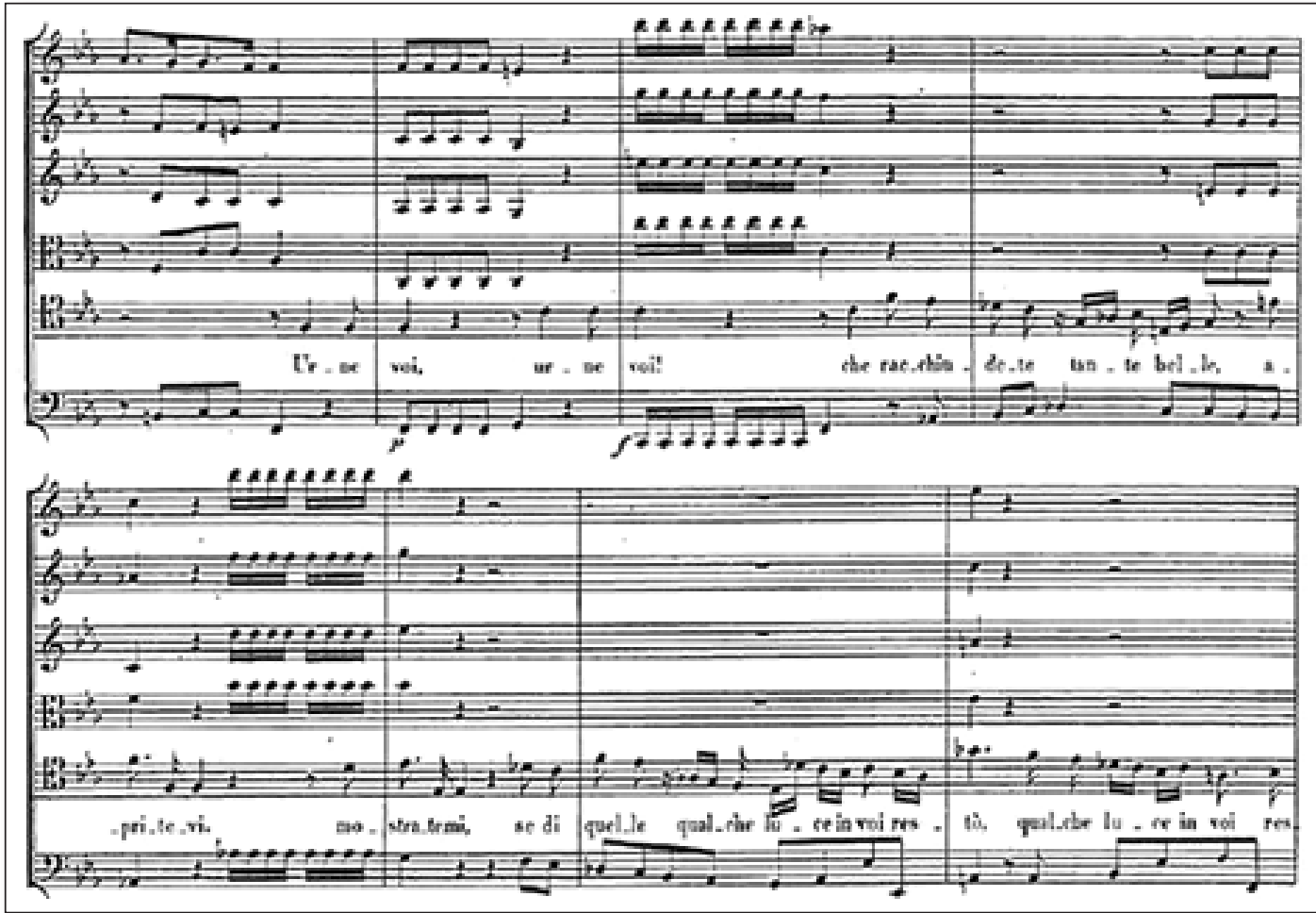

Fig. 8 Aria del Tempo «Urne voi».

Il trionfo del Tempo e del Disinganno cumple así, especialmente en sus primeras versiones en italiano, las más fieles al libreto original del cardenal Benedetto Pamphilj, con todas las funciones características de una colección de emblemas como si se tratara de auténticas picturae sonoras, aunque, en este caso, sean las arias y números de conjunto los que expliquen el sentido de los textos alegóricos compuestos por el académico y mecenas italiano. Por su calidad como libretista y aunque suelan apreciarse antes sus facetas de coleccionista y bibliófilo que la de poeta, merece plenamente ser reconocido también bajo este título.

\section{FUENTES}

Anónimo [1690]. Emblemata amatoria.

De la Feuille, D. [1691]. Devises et emblemes, Amsterdam.

Hensyus, D. [1616]. Niederduytsche poemata. Amsterdam, Willem Janssen, 1616.

PonA, F., S.I. [1645]. Cardiomorphoseos, sive ex corde desumpta emblemata sacra, Verona.

Pamphiliu, B. y Handel, G.F. [1865]. Il trionfo del tempo e del disinganno, Leipzig, Deutsche Händelgesellschaft.

Pamphiliu, B. y Handel, G.F. [1998]. Il trionfo del tempo e del disinganno, Turín, Teatro Regio.

Vaenius, O. (Otto van Veen) [1608]. Amorum emblemata, H. Verdussen. 


\section{BIBLIOGRAFÍA CRÍTICA}

Gianturco, C. [1994]. «Il trionfo del tempo e del disinganno. Four case-studies in determining Italian poetic-musical genres», Journal of the Royal Musical Association. 119. 1: 43-59. <http://dx.doi.org/10.1093/jrma/ 119.1.43>.

Montalto, L. [1955]. Un mecenate in Roma barocca: il cardinale Benedetto Pamphili (1653. 1730), Florencia, Sansoni.
Marx, H.J. [1983]. «Händel in Rom. Seine Beziehung zu Benedetto Card. Pamphilj», Händel-Jahrbuch, XXIX : 107-118.

Strohm, R. [1997]. Dramma per Musica. Italian opera seria of the Eighteen Century, New Haven, Yale University Press.

Weller, E. [1862]. Index pseudonimorum. Wörterbuch der Pseudonymen. Leipzig: Gustav Oëhme. 